\title{
A simultaneous pricing and inventory control model for a single product with capacitated working capital
}

\author{
Ismail Civelek \\ Dept. of Management, Western Kentucky University, Bowling Green, KY, U. S. A.
}

\section{Email address:}

ismail.civelek@wku.edu

\section{To cite this article:}

Ismail Civelek. A Simultaneous Pricing and Inventory Control Model for a Single Product with Capacitated Working Capital. International Journal of Business and Economics Research. Special Issue: Supply Chain Management: Its Theory and Applications.

Vol. 3, No. 6-1, 2014, pp. 1-5. doi: 10.11648/j.ijber.s.2014030601.11

\begin{abstract}
The simultaneous stochastic pricing and inventory management with capacitated cash-on-hand is a profit maximization problem faced by a firm, which has limited working capital for its liabilities. In addition to this working capital constraint, the company has to dynamically price its products and determine inventory levels to minimize its expected cost. In our study, we tackle this complicated problem by assuming a single product, periodic review inventory model with finite multiple periods, and imperfect market information. We also assume no fixed cost in order to relax the complexity of the problem and perform numerical analysis for providing managerial implications. We investigate several research questions to extend our understanding of this complicated but very practical problem faced by numerous decision-makers in organizations. A discussion of possible optimal policies for this complicated unanswered problem with working capital constraints is explored.
\end{abstract}

Keywords: Dynamic Pricing, Inventory Control, Supply Chain Management

\section{Introduction}

The stochastic cash balance problem, which includes pricing and inventory control simultaneously alongside constraints on working capital, is a profit maximization problem faced by a company. The decision-maker has to determine pricing of the product; replenishments of the stock while facing distress due to limited working cash-on-hand. In our study, we extend the problem investigated in [8] and [5]. In our problem setting, we assume a retailer that has huge amounts of debt to his or her creditors; hence, he or she has difficulty in obtaining cash to cover liabilities. Therefore, the only option to purchase the goods is using the cash on his or her hand, namely the working capital.

We assume that the retailer is in an imperfect competition market, so he or she can vary the demand by changing the price of the product. The retailer has a single product and uses the periodic-review inventory model in replenishing stocks. The demand is stochastic and we assume that the demands in consecutive periods are independent of each other. There is no fixed ordering cost and the retailer has to make the payment at the beginning of the period when he or she orders the products. Furthermore, the lead-time to receive goods from the supplier is assumed to be one period; thus, the retailer receives the goods at the end of the period. The stock-outs are backlogged completely when the inventory is replenished.

The retailer has to decide the price of the product dynamically and how much to order while considering the constraint on working capital. Thus, these pricing and inventory control decisions should be combined in such a policy that maximizes the expected revenue in this finite multiple period planning problem. Additionally, the retailer is allowed to both increase and decrease the price.

The problem of cash control has been essentially a finance and economic literature study; however, the current trend of scholarly works in operations management tends to build the connection between finance and operational decisions. After revenue management has been adopted from real industry problems, the academic community has been focusing on pricing of the perishable inventories, such as airline seats, hotel rooms and car rentals. Also, the operations management community has been trying to combine revenue management with manufacturing and supply chain management areas in order to capture both marketing and financial concerns.

In this paper we assume a retailer that has significant 
liabilities to his or her creditors. Due to being pressured by loan payments, the retailer uses his or her liquid assets, which refer to the working capital. Our main objective, which is to price the product, is very helpful to the decision-makers in practice. The problem of cash balancing and simultaneous decision-making also become very practical when we extend the problem setting to competitive markets. Therefore, decision-makers should make the financial and operational decisions jointly in order to succeed in a competitive market. In Section 2, we review the corresponding literature to position our study in the area of supply chain management. As for in Section 3, we present our model and notations; then, we discuss our findings in Section 4. Section 5 concludes our study with our main contributions, limitations of this study and future research directions.

\section{Literature Review}

The economists first consider the cash balance problem as managing the cost of transactions. The cash balance problem is simply the minimization of the expected cost of transactions faced by an economic entity, which makes repetitive decisions regarding the size of the cash balance. Reference [1] combines the inventory and monetary theory in a cash balance problem. Reference [17] investigates the cash problem in short term under uncertainty and uses a general linear programming approach in the short-term financing problem. Economists also try to combine the cash balance problem with other financial problems. Reference [7] considers the cash balance and dynamic portfolio problems together with transaction and transfer costs proportionally.

In management science literature, one of the most influential studies is given in [9], which analyzes the optimal cash balance levels by considering the cash balance problem as an inventory problem with holding and shortage costs, and shows the form of the optimal policy if the expected holding and shortage costs are convex and if deciding either to increase or to decrease the cash level does not involve a fixed cost. Reference [13] considers a stochastic cash balance problem, in which both fixed and proportional cost can be incurred whenever the cash balance is changed in either direction, by attempting to capture the relationship between the cash balance problem and inventory problems firstly studied by [4].

As the cash management problem emanates from the lack of synchronization between cash inflows and outflows, the decision-maker should consider how to finance cash requirements when cash outflows exceed inflows or how to invest a cash surplus when cash inflows are more than outflows. Reference [14] studies the unequal-period model for cash balance problem and develops a linear programming model for solving the problem in unequal periods. The finite horizon cash balance problem with charges levied against the balance is studied by [13] and [15] and by presenting the optimality of a two-sided (s, S) policy. Reference [16] also presents the equivalent formulations of the stochastic cash balance problem. Reference [11] reveals a model for cash balance management and expresses the optimal policy, as "never have any more cash on hand than is necessary to satisfy the constraint."

Reference [6] studies a continuous time model of cash management by formulating with stochastic demand and allowing positive and negative cash balances. Reference [6] also considers the problem with both fixed and proportional costs. Reference [3] develops a perfect planning horizon procedure for the simple cash balance problem. The objective is to schedule the selling and buying of earning assets; hence, all the positive demands are met at minimum cost. This study also presents a forward dynamic programming algorithm to solve the problem. Reference [12] presents a stochastic linear programming formulation of a firm's short term planning problem under uncertainty, and concludes, that even with symmetric penalty costs and distributions, the mean model is meaningfully inferior to the stochastic linear program.

Reference [5], in a recent article, has proposed a new approach to the cash balance problem with fixed ordering cost by introducing new concepts, K-convexity and (K, Q)-convexity, to the literature of cash balance management problems. Reference [8] investigates strategies on pricing and inventory replenishment simultaneously with having uncertainty in the demand. Demand depends on the price with general stochastic functions and demands in consecutive periods are independent of each other. Also, [8] considers fully backlogging of the stock-outs. Reference [8] specifically analyzes the single item, periodic review inventory problem without a fixed ordering cost by using dynamic pricing strategies in both finite and infinite time horizon. In the results, this article compares dynamic versus static pricing strategy and bi-directional dynamic pricing versus permitting only markdowns strategy, and analyzes the effects of demand uncertainty and price elasticity. Reference [8] assumes that the holding and backlogging costs are convex functions to satisfy the concavity of the revenue function. However, under capacity constraints on working capital, those convexity assumptions about the holding and stock-out costs may not hold.

As an extension to the study of [8], [5] considers the same problem allowing fixed ordering cost. This paper shows that the profit-to-go functions are k-concave, and ( $, \mathrm{S}, \mathrm{p}$ ) policy is optimal when the demand model is additive. Furthermore, [5] states that k-concavity of the profit-to-go functions is not necessary for general demand models, so $(\mathrm{s}, \mathrm{S}, \mathrm{p})$ policy may not be optimal. For the general demand cases, [5] introduces the symmetric k-concave functions and presents the characterization of the optimality. Moreover, [5] considers a special case, in which the fixed cost is zero, and shows that a base stock list price policy is optimal. Also, [5] gives possible extensions and concluding remarks for further study like our approach that considers the problem with constraints on working capital.

In this study, we assume a retailer that has huge amounts of debt to his or her creditors; hence, he or she has difficulty to get loans to honor his or her liabilities. The only option to purchase the goods is using the cash on hand. This 
complicated problem has numerous practical implications for real industry settings. Our main objective, which is to price the product, is very helpful to the decision-makers in practice. The problem also becomes very practical when we extend it to competitive markets. Therefore, decision-makers should make the financial and operational decisions jointly in order to succeed in a competitive market.

\section{The Model}

The notation we use in this paper is similar to [5] and [8] due to easier tracking of our model and results. In this stochastic cash balancing problem, we assume that there is no fixed ordering cost. This is a common assumption in the literature for simultaneous financial and operational decisions due to tractability of the model [8]. The notation we use in this problem is the following:

$T$ : Finite planning time horizon.

$t$ : Time period for $t, t=1,2, \ldots$

$w_{t}$ : Demand in period $t$.

$p_{t}$ : Price in period $t$.

$I_{t}$ : Inventory position at the end of period $t$.

$q_{t}$ : Order size given at the beginning of period $t$.

$C_{t}$ : Working capital (cash-on-hand) at the end of period $t$.

$L_{t}$ : Loan payment to the creditors at the end of period $t$.

$n_{t}$ : Unit ordering cost at the beginning of period $t$.

$h_{t}$ : Unit inventory holding cost at the end of period $t$.

We set an initial value for the working capital and the inventory level: $C_{0}=K$ and $I_{0}=0$, where $K \geq 0$; then, the working capital of the retailer for $t>0$ has the following form:

$$
C_{t}=C_{t-1}+w_{t} p_{t}-h_{t} I_{t}-n_{t} q_{t}-L_{t} .
$$

The retailer has to decide the price of the product, $p_{t}$, and the inventory replenishment quantity, $q_{t}$, at the beginning of each period $t$. The planning horizon is finite, $T$; hence the decision vectors, $Q$ and $P$; the stochastic demand vector, $W$; the inventory holding cost vector, $H$; the unit ordering cost vector, $N$, and the loan payment vector are the following:

$$
\begin{aligned}
\mathrm{Q} & =\left[\begin{array}{llll}
\mathrm{q}_{1} & \mathrm{q}_{2} & \ldots & \mathrm{q}_{\mathrm{T}}
\end{array}\right], \\
\mathrm{P} & =\left[\begin{array}{llll}
\mathrm{p}_{1} & \mathrm{p}_{2} & \ldots & \mathrm{p}_{\mathrm{T}}
\end{array}\right], \\
\mathrm{W} & =\left[\begin{array}{llll}
\mathrm{w}_{1} & \mathrm{w}_{2} & \ldots & \mathrm{w}_{\mathrm{T}}
\end{array}\right] . \\
\mathrm{H} & =\left[\begin{array}{llll}
\mathrm{h}_{1} & \mathrm{~h}_{2} & \ldots & \mathrm{h}_{\mathrm{T}}
\end{array}\right] . \\
\mathrm{N} & =\left[\begin{array}{llll}
\mathrm{n}_{1} & \mathrm{n}_{2} & \ldots & \mathrm{n}_{\mathrm{T}}
\end{array}\right] . \\
\mathrm{L} & =\left[\begin{array}{llll}
\mathrm{L}_{1} & \mathrm{~L}_{2} & \ldots & \mathrm{L}_{\mathrm{T}}
\end{array}\right] .
\end{aligned}
$$

The retailer's problem is in the following form as the maximization of the expected profit over $T$ periods by deciding the pricing, $P$, and inventory control, $Q$, simultaneously. Besides working capital constraints, there are cash balance and nonnegative constraints in this maximization problem. Therefore, the retailer's optimization problem by simultaneously deciding $P$ and $Q$ :

$$
\begin{aligned}
& \text { Max WP' }-H I^{\prime}-N Q \\
& \text { Subject to } \\
& C_{t}=C_{t-1}+w_{t} p_{t}-h_{t} I_{t}-n_{t} q_{t}-L_{t}, t=1, \ldots, T . \\
& I_{t}=I_{t-1}+q_{t}-w_{t}, t=1, \ldots, T . \\
& I_{0}=0, \\
& C_{0}=K, \\
& C_{t}, I_{t}, q_{t}, p_{t} \geq 0, t=1, \ldots, T .
\end{aligned}
$$

\section{Results and Discussion}

In this stochastic pricing and inventory control model, there is no structural optimal policy due the constraint of working capital. For example, both [5] and [8] propose a policy that involves deciding the inventory level, then the pricing of the product. Reference [5] calls this policy as (s, S, p); however, this policy does not work for the constrained problem. In our setting with capacitated working capital, the optimal policy might be (s, S, p, C) where C stands for the capacity on the working capital.

Regarding the numerical results, we assume that the inventory holding cost, the unit ordering costs and the loan payment per period are fixed over the planning horizon: $h_{t}=$ $1, n_{t}=1$ and for $L_{t}=100, t=1, \ldots, T$. The initial working capital and starting inventory level are set to $C_{0}=K=1000$ and $I_{0}=0$. We consider only three periods, $T=3$, for the planning horizon due to high computational complexity. The demand for each period is independent and uniformly distributed between 0 and 10 . We set the possible prices as Low (1), Medium (5) or High (100) and, similarly, order quantity as zero, Low (1), Medium (5) or High (100) to reduce the computational complexity. We simulate the demand stream for three periods using Matlab and calculate the expected period with optimal $P$ and $Q$. We choose the simulation run length as 100,000 . In the initial setting, the optimal prices are all equal to $100, p_{1}=p_{2}=p_{3}=100$, due to the assumption of no competitor. Moreover, the optimal order sizes are $q_{1}=100$ and $q_{2}=q_{3}=0$.

Table 1. Impact of the holding cost on pricing and inventory decisions

\begin{tabular}{llll}
\hline $\boldsymbol{h}$ & $\boldsymbol{P}$ & $\boldsymbol{Q}$ & Expected Profit \\
\hline 1 & $(100,100,100)$ & $(100,0,0)$ & 22.39 \\
5 & $(100,100,100)$ & $(5,100,0)$ & 14.71 \\
10 & $(100,100,100)$ & $(5,5,5)$ & 4.22 \\
100 & $(100,100,100)$ & $(5,5,5)$ & 3.85 \\
\hline
\end{tabular}

In Table 1, we investigate the impact of the inventory holding cost, h, on the optimal pricing and inventory control policies. The expected profit of the retailer decreases as the inventory holding cost increases. The decision-maker also orders less, because handling inventory gets more expensive. This result implies that there is no known structural optimal policy for this simultaneous pricing and inventory control problem, in which a state-dependent policy may be optimal. 
Table 2. Impact of the purchasing cost on pricing and inventory decisions

\begin{tabular}{llll}
\hline $\boldsymbol{n}$ & $\boldsymbol{P}$ & $\boldsymbol{Q}$ & Expected Profit \\
\hline 1 & $(100,100,100)$ & $(100,0,0)$ & 22.39 \\
5 & $(100,100,100)$ & $(5,100,0)$ & 15.69 \\
10 & $(100,100,100)$ & $(5,5,5)$ & 4.29 \\
50 & $(100,100,100)$ & $(5,5,5)$ & 2.56 \\
\hline
\end{tabular}

Table 2 shows the impact of the unit purchasing cost on the optimal pricing and inventory control policies. Similar to Table 1, the expected profit of the retailer decreases as the unit purchasing cost increases due to increased procurement costs. Also, the decision-maker orders less due to lower profit margins.

Table 3. Impact of the loan payment on pricing and inventory decisions

\begin{tabular}{llll}
\hline $\boldsymbol{L}$ & $\boldsymbol{P}$ & $\boldsymbol{Q}$ & Expected Profit \\
\hline 10 & $(100,100,100)$ & $(100,0,0)$ & 26.10 \\
100 & $(100,100,100)$ & $(100,0,0)$ & 22.39 \\
500 & $(100,100,100)$ & $(5,100,0)$ & 21.43 \\
800 & $(100,100,100)$ & $(1,100,0)$ & 17.38 \\
\hline
\end{tabular}

In Table 3, we analyze the impact of the periodic loan payments on the optimal pricing and inventory control policies. The expected profit of the retailer diminishes as the periodic loan payment to the creditors increases. This result also points out the possibility of a state-dependent optimal policy.

As for the discussion of our model and results, we believe that a state-dependent optimal policy or a $(\mathrm{s}, \mathrm{S}, \mathrm{p}, \mathrm{C})$ policy may be possible, in which $\mathrm{C}$ stands for the capacity on the working capital, to combine dynamic pricing strategy and inventory control decisions. Both [5] and [8] propose their policies by deciding pricing first, then inventory replenishment. Moreover, this problem becomes very complicated if there are multiple products due to substitutions and cross-price elasticity among these products. If there are competitors in the market, our problem needs to embrace game theoretical formulation, which involves financial condition and market share of the competitor.

Regarding the possibility of obtaining loans from a bank, asset-based financing has to be considered in our problem setting. The available cash in each period, which is a function of assets and liabilities, needs to be updated periodically according to the dynamics of the retailer's pricing and inventory control decisions. Reference [2] shows the importance of joint consideration of production and financial decisions in a start-up setting, in which a company's ability to grow is primarily constrained by its limited capital and dependence on banks' credits. Therefore, the retailer needs to decide on the loan amount limited by the bank and the order size.

In light of other inventory control policies, the problem of simultaneous pricing and inventory control of a single product would be quite complicated in a continuous review policy with capacitated working capital. Reference [9] considers a continuous review policy to determine pricing and inventory control simultaneously; however, it does not consider any capacity in the problem setting. As for backlogging, if the stock-outs are not fully backlogged, the retailer loses possible sales and cash inflow to support periodic loan payments. The retailer also loses information regarding the demand that implies an optimal policy focusing on the estimation of the lost sales.

Considering the stochastic nature of the demand, Bayesian updating can be used to model the demand stream. In this approach, firstly, we have to select the prior demand distribution in a conjugate family and then update the demand at the end of each period. If the demand has a very high variation that cannot be captured in the original problem setting, Bayesian updating can be very useful. However, Bayesian updating of the demand might be very costly regarding computational issues, because we have to use either Gibbs sampling, slice sampler or Monte Carlo simulation to compute the posterior distributions in each period. Therefore, Bayesian updating of the demand would be computationally very expensive.

\section{Conclusions}

In this study, we consider the problem of combined pricing and inventory control with a capacity on working capital. This complicated problem for a retailer is a profit maximization problem faced by a company, which has limited cash-on-hand to pay both his or her operating costs and loan payments to his or her creditors. Moreover, the firm has to dynamically price its products and determine inventory levels to minimize its expected cost. This paper attempts to analyze this complicated problem by assuming a single product, periodic review inventory model and finite multiple periods. We also assume no fixed cost in order to relax the complexity of the problem and perform numerical analysis for providing managerial implications. We investigate several research questions to extend our understanding of this complicated, but very practical, problem faced by numerous decision-makers in various organizations. We provide discussion of possible optimal policies for this complicated unanswered problem with working capital constraints. Furthermore, we discuss possible extensions to the model with different demand settings and inventory control policies.

Our numerical study shows that the expected profit of the retailer decreases when the inventory holding cost, the unit purchasing cost or the periodic loan payment increase. Moreover, the numerical results suggest a state-dependent policy may be optimal for this complicated problem due to the lack of any known structure for the expected profit function. This problem of simultaneous pricing and inventory control of a single product over multiple periods has been an unanswered research question in the management science literature. Therefore, we attempt to investigate possible optimal policies for this problem and decide what type of analytical approach would be appropriate for different demand, inventory control policy and financing option settings. We believe that analyzing this problem for a single period would open future research discussion to extend into multiple product problems. 


\section{References}

[1] W. J. Baumol. "The transactions demand for cash: an inventory theoretic approach,” The Quarterly Journal of Economics, Vol. 66, No. 4, pp. 545-556, 1952.

[2] J. Buzacott and R. Q. Zhang. "Inventory management with asset-based financing," Management Science, Vol. 50, No. 9, pp. 1274-1292, 2004.

[3] S. Chand and T. E. Morton. "A perfect planning horizon procedure for a deterministic cash balance problem," Management Science, Vol. 28, No. 6, pp. 652-669, 1982.

[4] A. J. Clark and E. H. Scarf. "Optimal policies for a multi-echelon inventory problem," Management Science, Vol. 6, No. 4, pp. 475-490, 1960.

[5] X. Chen and D. Simchi-Levi. "Coordinating inventory control and pricing strategies with random demand and fixed ordering cost: The finite horizon case," Operations Research, Vol. 52, No. 6, pp. 887-896, 2004.

[6] G. M. Constantinides. "Stochastic cash management with fixed and proportional transaction costs," Management Science, Vol. 22, No. 12, pp. 1320-1331, 1976.

[7] G. D. Eppen and E. F. Fama. "Cash balance and simple dynamic portfolio problems with proportional costs," International Economic Review, Vol. 10, No. 2, pp. 119-133, 1969.

[8] A. Federgruen and A. Heching. "Combined pricing and inventory control under uncertainty," Operations Research, Vol. 47, No. 3, pp. 454-475, 1999.

[9] Y. Feng and F. Chen. "Joint Pricing and inventory control with setup costs and demand uncertainty," Working paper, 2002.

[10] N. M. Girgis. "Optimal cash balance levels," Management Science, Vol. 15, No.3, pp. 130-140, 1968.

[11] D. P. Heyman. "A model for cash balance management," Management Science, Vol. 19, No. 12, pp. 1407-1413, 1973.

[12] J. G. Kallberg, R. W. White and W. T. Ziemba. "Short term financial planning under uncertainty," Management Science, Vol. 28, No. 6, pp. 670-682, 1982.

[13] E, H. Neave. "The stochastic cash balance problem with fixed costs for increases and decreases," Management Science, Vol. 16, No. 7, pp. 472-490, 1970.

[14] Y. E. Orgler. "An unequaled-period model for cash management decisions," Management Science, Vol. 18, No. 2, pp. B77-B92, 1969.

[15] E. Porteus. "Equivalent formulations of the stochastic cash balance problem," Management Science, Vol. 19, No. 3, pp. 250-253, 1972.

[16] E. Porteus. "The stochastic cash balance problem with charges levied against the balance," Management Science, Vol. 18, No. 1, pp. 600-602, 1972.

[17] A. A. Robicheck, D. Teichroew and J. M. Jones. "Optimal short term financing decisions," Management Science, Vol. 12, No. 1, pp. 1-36, 1965. 